\title{
Experimental study of riverbank protection with bio-engineering techniques
}

\author{
Sara Posi ${ }^{1}$, Lucas Montabonnet ${ }^{2}$, Alain Recking ${ }^{2, *}$, André Evette ${ }^{3}$, Hervé Bellot ${ }^{2}$, \\ Frédéric Ousset ${ }^{2}$, Xavier Ravanat ${ }^{2}$, Guillaume Piton ${ }^{2}$ and Luca Solari ${ }^{1}$ \\ ${ }^{1}$ University of Florence, Department of Civil and Environmental Engineering (DICEA), Florence, \\ ITALY \\ ${ }^{2}$ Univ. Grenoble Alpes, IRSTEA UR ETNA, Domaine Universitaire, 38402 Saint-Martin-d'Hères \\ cedex, France \\ ${ }^{3}$ Univ. Grenoble Alpes, IRSTEA UR LESSEM, Domaine Universitaire, 38402 Saint- \\ Martin-d'Hères cedex, France
}

\begin{abstract}
River management implies in many situation to control the river bank stability. Bio-engineering techniques are used as an alternative to rip-rap. These techniques are not new but a renewed interest was observed during the last decade. However the design of such bank protection is still largely based an expert evaluation of each situation, and we still crudely lack a real state of the art, based on mechanistic consideration of forces exerted by the river. We present the results of preliminary flume experiments aiming to study the resistance of river bank protections using bio-engineering techniques. The final applied objectives will be to propose a framework for a good use of such technique, accounting for the river morphodynamics context.
\end{abstract}

\section{Introduction}

Rivers morphodynamics depends on the ability of the flow to erode the river banks. This is particularly true in braided rivers where it has been clearly established that the variety of forms is directly linked to the upstream sediment supply and river bank erodibility [Ashmore et al., 2011]. However most rivers are human impacted, with the first consequence being a fixation of the banks by civil engineering works or levees. The resulting typical situation is a bed incision and narrowing between fixed banks usually covered by vegetation and in parallel, an increase of human stakes in the nearby area, sometimes inside the river flood plain.

This long term landscape evolution makes it difficult today to deal with rivers renaturation. Indeed, many projects ideally envisage restoring a non-constrained morphodynamic, but restoration objectives must account for the delicate question of risk management: roads, structures, inhabitation, agricultural fields must be protected from bank erosions.

\footnotetext{
* Corresponding author: alain.recking@irstea.fr
} 
Civil engineering techniques, such as concrete or rip-rap protections, have been used during many decades. Whereas these techniques proved to be resistant to the flow shear stress in many situations, they are often oversized -especially in mountainous streams- and reduce considerably the ecological values of the protected bank: lower plant species diversity, increasing colonization of invasive species and limitation of wildlife habitats (Cavaillé et al. 2013, 2015).

Alternative techniques exist, and more particularly bio-engineering techniques. These techniques are not new since they were already used during the nineteen century for mountain streams restoration (Evette et al. 2009), and a renewed interest could be observed during the last decade. However the design of such bank protection is still largely based an expert evaluation of each situation, and we still crudely lack a real state of the art, based on mechanistic consideration of forces exerted by the river and of processes inducing failures of the structures.

We present the results of preliminary flume experiments aiming to study the resistance of river bank protections using bio-engineering techniques. The final applied objectives will be to propose a framework for a good use of each technique, accounting for the river morphodynamics context.

\section{Experimental set-up}

The experiments were performed in a $6 \mathrm{~m}$ long, $1.25 \mathrm{~m}$ wide tilting flume at Irstea. The slope was fixed at $2 \%$ in order to be representative of energetic rivers (typical from alpines rivers), and also because using such a steep slope permit to accelerate the erosion processes and to cover a large set of experiments.

Each experiment considered the flow in a trapezoidal channel (major base $\mathrm{L}=20 \mathrm{~cm}$, minor base $\mathrm{l}=10 \mathrm{~cm}$, height $\mathrm{H}=5 \mathrm{~cm}$ ) meandering in a valley floor (Figure 1), with erodible banks located in each bends. The bend had different curvature, obtained by decreasing the associated curvature radius from infinity (flow parallel to the bank), to $R=3.25 \mathrm{~m}, \mathrm{R}=2.55 \mathrm{~m}$ and finally $\mathrm{R}=1.43 \mathrm{~m}$

The valley floor was composed of poorly mobile (fixed) coarse sediment mixture $\left(D_{\mathrm{m}}=5.6 \mathrm{~mm}, \mathrm{D}_{50}=3 \mathrm{~mm}, \mathrm{D}_{84}=8 \mathrm{~mm}, \mathrm{D}_{95}=20 \mathrm{~mm}\right)$.
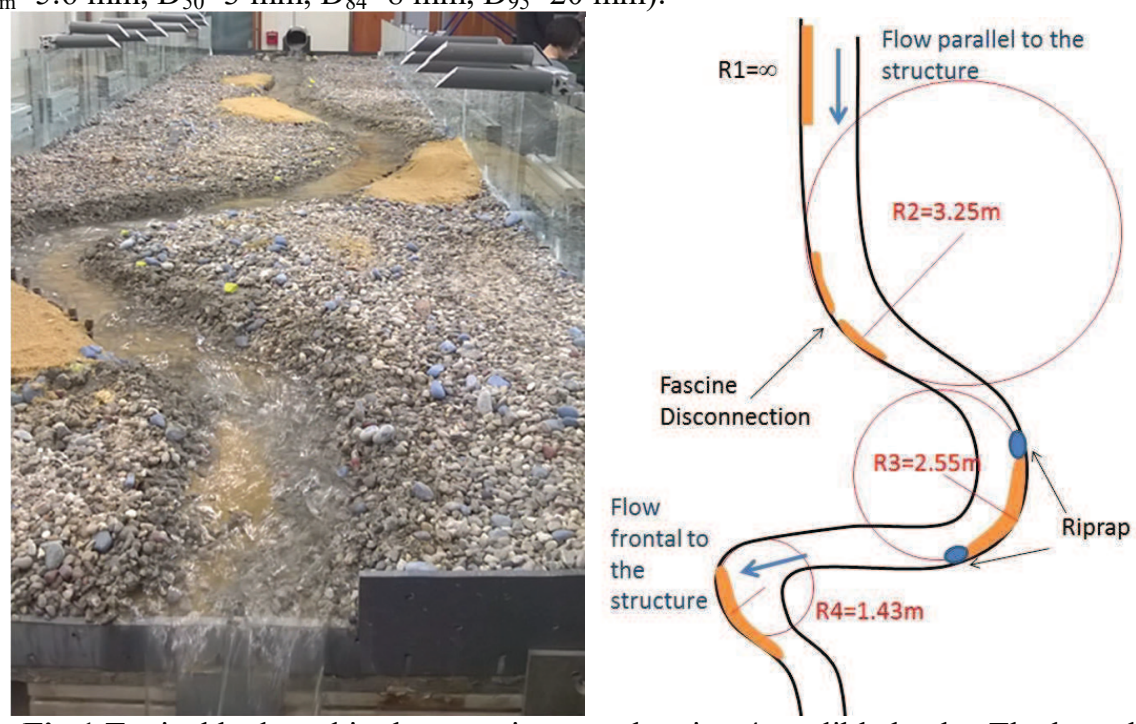

Fig.1 Typical bed used in the experiments, showing 4 erodible banks. The lateral tubes support targets for photogrammetry measurements 
Because river bank stability is closely dependent on the nature of the material composing the bed, and because it is obviously impossible to test infinity of situations, we choose to test the more disadvantageous case, with the erodible material being composed of non-cohesive fine sands $(\mathrm{D} 50=0.7 \mathrm{~mm})$.

The bank protection technique tested was fascines, which consists in an arrangement of materials made with salix and fixed in the river bed against the erodible bank with wood sticks (Fig. 2).

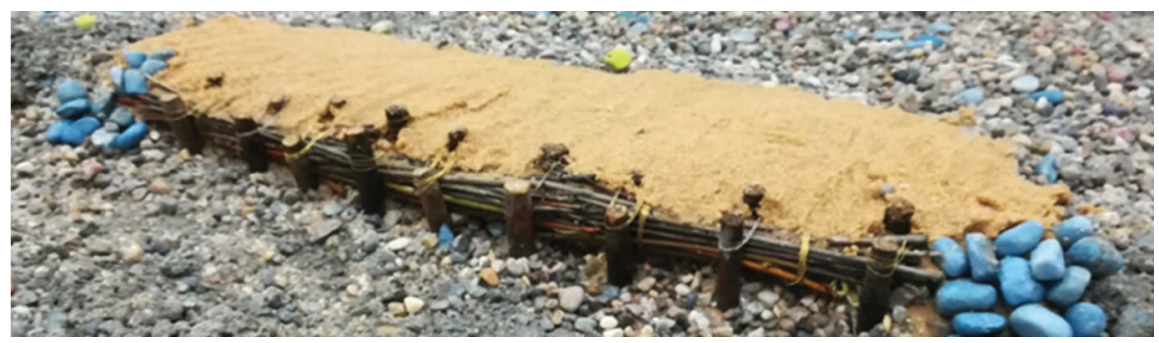

Fig.2A fascine with ripraps upstream and downstream

The deterioration of a bank protection structure can potentially originate from either the direct action of flow shear stress, or by local scouring destabilizing the bank around the structure. Because preliminary experiments $[\mathrm{Perez}, 2016]$ have shown that the major source of destruction was local scouring, the experimental plan has finally consisted in investigating not the detailed flow field, but rather effect of varying structure design in changing morphological contexts.

We could identify 5 weakness points in a standard design, from which could originate a disorder: the upstream rip-rap, the downstream rip-rap, the basal rip-rap i.e., connexions between the fascine and the erodible bank upstream, downstream and below the structure, connexion between 2 consecutive fascines, and overtopping of the structure.

The basal connection between the bed and the fascine proved to be a key weak point depending on its erodibility and protection (Fig. 3).
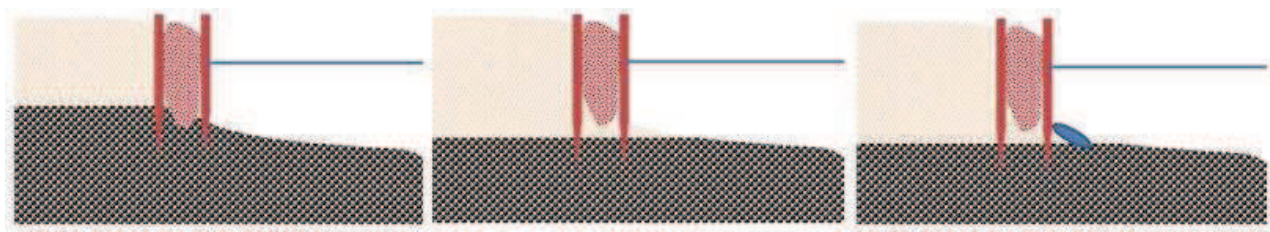

Fig.3 Basal connection of the erodible bank a) disconnected, b) connected, c) connected with riprap

Each configuration of Fig. 3 was tested with consideration of four typical discharges (Table 1):

- low discharge : LQ, the flow reach only the basal part of the structure),

- medium discharge (MQ, the flow reach the structure),

- $\quad$ high discharge (HQ, bankfull flow), and

- $\quad$ exceptional discharge (EQ, inundating the flood plain).

Each run lasted $1 \mathrm{~h}$ and we measured the bank failure speed evolution in controlled sections. The bed topography and bank erosions were also measured by the Structure from Motion technique (Westoby et al. 2012). The surface flow velocity was measured by particle tracking. 
Table1. Experimental plan

\begin{tabular}{|c|c|c|c|c|}
\hline & Low Q & Med Q & High Q & Ex Q \\
\hline Reference & $\mathrm{X}$ & $\mathrm{X}$ & $\mathrm{X}$ & $\mathrm{X}$ \\
\hline \multicolumn{5}{|c|}{ Basal connection (between erodible material and fixed bed) } \\
\hline Full protection FP & $\mathrm{X}$ & $\mathrm{X}$ & $\mathrm{X}$ & $\mathrm{X}$ \\
\hline No riprap upstream & $\mathrm{X}$ & $\mathrm{X}$ & $\mathrm{X}$ & \\
\hline No riprap downstream & & & $\mathrm{X}$ & \\
\hline No riprap up and downstream & & & $\mathrm{X}$ & \\
\hline No basal riprap & $\mathrm{X}$ & $\mathrm{X}$ & $\mathrm{X}$ & \\
\hline \multicolumn{5}{|l|}{ No basal and upstream riprap } \\
\hline \multicolumn{5}{|l|}{ No basal and downstream riprap } \\
\hline No riprap at all & & $\mathrm{X}$ & $\mathrm{X}$ & \\
\hline Fascine disconnection & & $\mathrm{X}$ & $\mathrm{X}$ & \\
\hline \multicolumn{5}{|c|}{ Basal disconnection (between erodible material and fixed bed) } \\
\hline Full protection FP & $\mathrm{X}$ & $\mathrm{X}$ & $\mathrm{X}$ & \\
\hline No riprap upstream & & $\mathrm{X}$ & $\mathrm{X}$ & \\
\hline No riprap downstream & & $\mathrm{X}$ & $\mathrm{X}$ & \\
\hline \multicolumn{5}{|l|}{ No riprap up and downstream } \\
\hline No basal riprap & $\mathrm{X}$ & $\mathrm{X}$ & $\mathrm{X}$ & \\
\hline No basal and upstream riprap & $\mathrm{X}$ & $\mathrm{X}$ & & \\
\hline No basal and downstream riprap & $\mathrm{X}$ & $\mathrm{X}$ & & \\
\hline \multicolumn{5}{|l|}{ No riprap at all } \\
\hline Fascine disconnection & & & & \\
\hline
\end{tabular}

The quantity of material eroded could be measured with a diachronic analysis of photogrammetry.
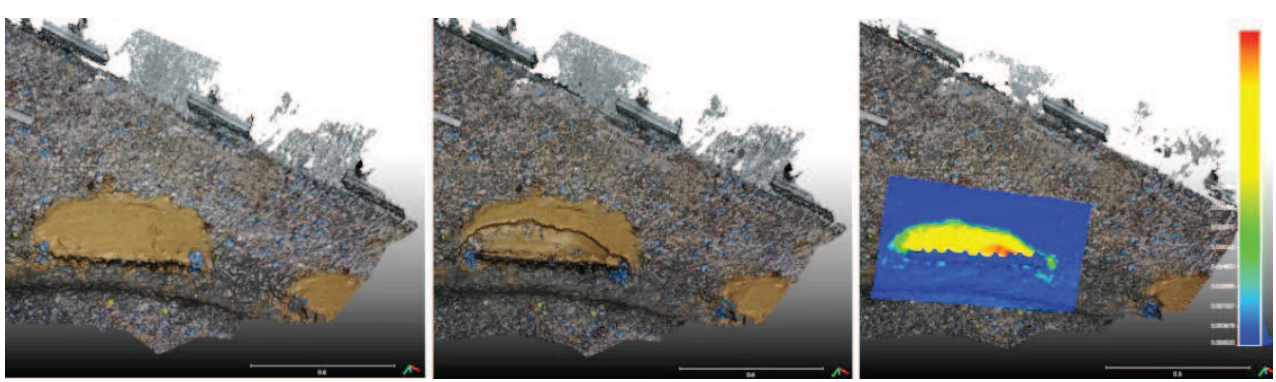

Fig.4 Example of diachronic analysis a) before the run, b) after the run, and c) difference The color scale varies from blue (absence of erosion) to red (maximum erosion).

\section{Results}

The hydraulics for each condition is resumed in the following table.

The first observation is that the flow velocity was higher in the less curveted bends, which can be explained by the high energy dissipation by flow distortion inside the bends. The velocity drop also when submerging the flood plain, which may not be inconsistent with the momentum exchange occurring between the flood plain and the channel in such situation [Proust et al., 2010]. The hydraulic radius Rh measured for exceptional discharge was of same order than the one measured for medium, and even slightly smaller, but this could be 
due to the uncertainties as measurements were done visually with a point gauge and the free surface was highly perturbed for such flows.

Table2. Hydraulics

\begin{tabular}{|l|l|l|l|l|}
\hline & Low & Medium & High & Exceptional \\
\hline $\mathrm{Q}(\mathrm{l} / \mathrm{s})$ & 0.89 & 1.68 & 2.5 & 3.6 \\
\hline $\mathrm{Rh}(\mathrm{m})$ & 1.76 & 2.19 & 2.27 & 2.15 \\
\hline $\mathrm{U}(\mathrm{m} / \mathrm{s})(\mathrm{R}=\infty, \mathrm{R}=3.25)$ & 0.56 & 0.76 & 0.84 & 0.70 \\
\hline $\mathrm{U}(\mathrm{m} / \mathrm{s})(\mathrm{R}=2.55, \mathrm{R}=1.43)$ & 0.45 & 0.58 & 0.61 & 0.67 \\
\hline$\tau^{*}($ bed $)$ & $\approx 0$ & $\approx 0$ & $\approx 0$ & $\approx 0$ \\
\hline$\tau^{*}$ (riprap $\left.\mathrm{D}=2 \mathrm{~cm}\right)$ & 0.006 & 0.012 & 0.018 & 0.021 \\
\hline$\tau^{*}$ (erodible material) & 0.17 & 0.35 & 0.52 & 0.6 \\
\hline
\end{tabular}

The Shields stress $\tau^{*}$ computed with equation (1) is near zero for the fixed bed, and cannot explain the structure destruction. The values are still low for ripraps $\left(\tau^{*}<\tau \mathrm{c}^{*}=0.03-\right.$ 0.05) which means that riprap destabilisations result from local scouring. The Shields stress is very high for the erodible material.

$$
\tau^{*}=\frac{h S}{1.65 D}
$$

Where $\mathrm{h}$ is the water depth, $\mathrm{S}$ the slope and $\mathrm{D}$ the sediment diameter.

The main structure disorders are summarised in table 3 with a colour code from green to red indicating the degradation importance.

Table3. Structure disorders (green: no disorder; yellow: weak and local disorder, orange: well developed disorder; red: quasi destruction, white: no test)

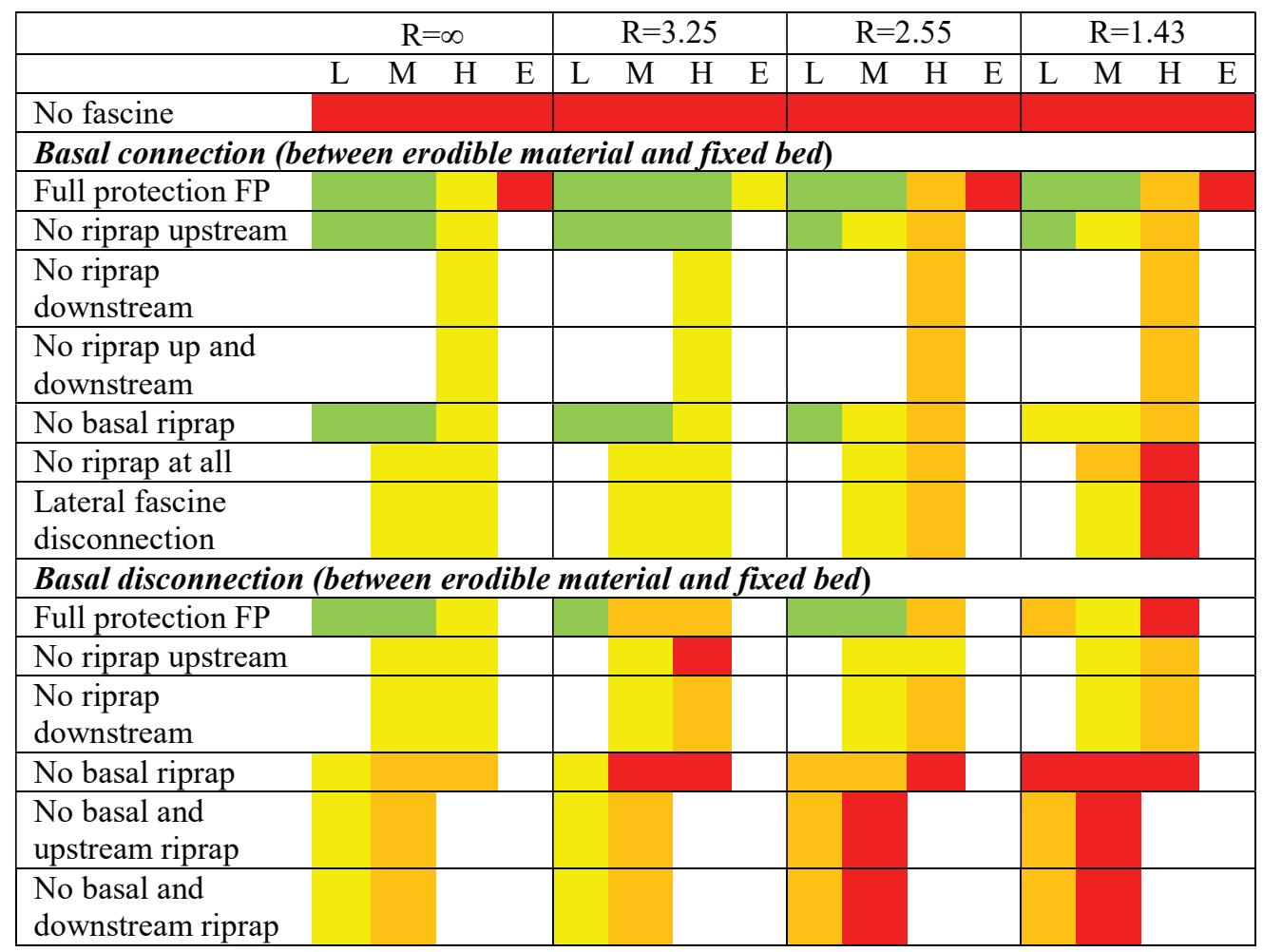


This "picture" of the complete experiment indicates that:

- Fascines can be very efficient to protect the bank when they are correctly designed;

- Most degradations are cause by scouring and fascine extraction occurred in no experiment;

- The erosions increase with the angle between the structure and the flow: it was minimum when the flow is parallel to the structure, and maximum when the flow is frontal;

- All situations promoting a flow circulation inside the bank aggravate the internal erosion: this is the case when upstream ripraps are removed; this is also the case when the flow is frontal to the structure;

- Regressive erosion plays a key role for large amplitude destruction;

- The most biggest failures were associated with the basal connection to the flow.

In terms of pathology, we could identify the principal ones:

- Top erosion due to a flow overtopping the fascine when the water depth is sufficiently high (Fig. 5);

- Erosion at the base of the fascine leading to scoring and local bank collapse (Fig. 6).

- Back erosion affecting the downstream part of the erodible bank (Fig.7);

- Total collapse when back erosion is combined with local bank collapse caused by basal scouring (combination of Fig.6 and 7)

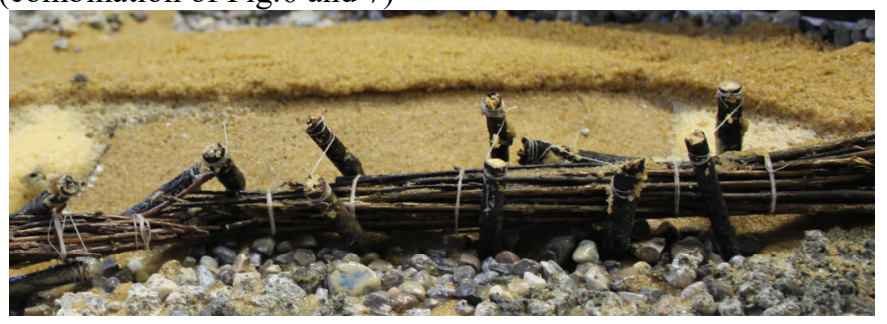

Fig.5 Top erosion (test: connection present, high discharge, full protection).

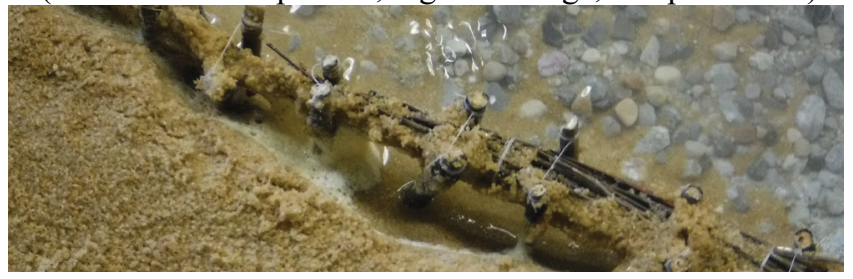

Fig.6 Basal erosion (test: connection absent, medium discharge, no rip rap upstream).

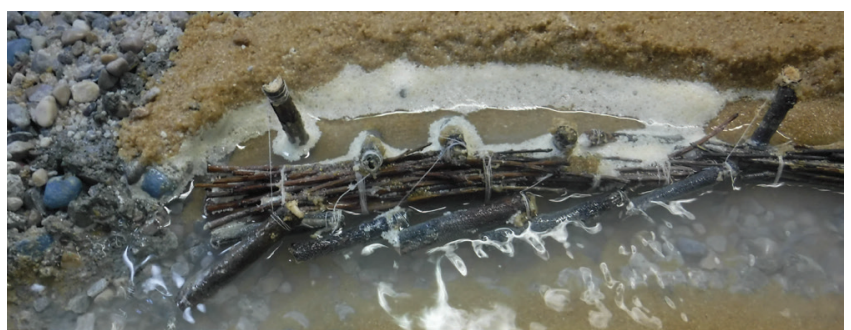

Fig. 7 Downstream back erosion (test: connection present, high discharge, no rip rap downstream). 
Fig. 8 compares the speed of erosion with and without a basal protection. In the $\mathrm{x}$-axis plot the time in minutes while the y-axis plot the ratio between the length of the eroded bank and the initial length of the bank. It shows how the absence of basal connection strongly affects both on the speed of the process (slope of the curve) and the quantity of material eroded (maximum value reach on the y-axis).

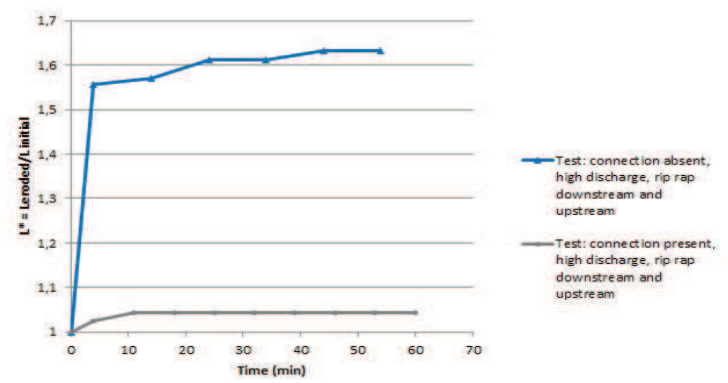

Fig 8 Comparison, in terms of speed of erosion, with basal and no basal connection for the test: high discharge, upstream and downstream rip rap.
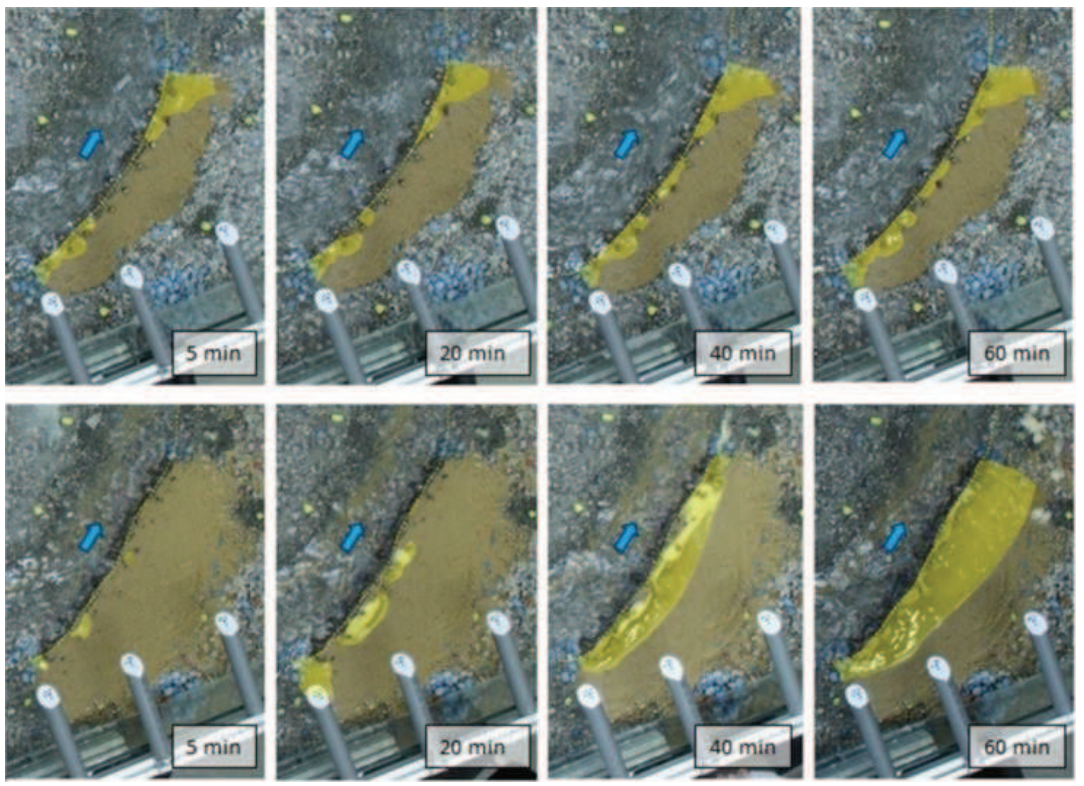

Fig.9 Process of erosion in the third bend with a condition of full rip rap protection and high discharge (different time are considered: 5/20/40/60 minutes). The upper part of the figure corresponds to a protection with no basal protection, while in the down part of the figure was with basal protection and top-erosion. Light yellow polygons figure the top bank erosion.

Figure 9 illustrates the process of erosion associated with the curve plotted in Fig 8. In absence of protection, high speed erosions are located just behind the fascine and concentrate the flow, leading to deep erosion, bank collapse and structure destruction. When the basal rip rap protection are present (below), the flow is not captured by scours and overpasses the bank leading to top erosions by direct action of flow shear stress over 
the erodible bank: the areal extension is larger, but superficial; such top bank erosion does not threaten the fascine and is easier to repair afterward.

We conclude from this set of experiments that among the variety of scenario tested, the basal protection revealed to play a key role on the structure resistance to the flow.

\section{Conclusion and discussion}

This paper presents preliminary results of a series of experiments aiming to better understand mechanisms leading to the failure of bank protection structures made with bioengineering techniques. The case of fascines was considered.

The set of experiment presented was designed to investigate a maximum of combinations of structure design and flow conditions (considered through discharge and bend curvature).

It was clearly shown that fascines can be very efficient for protecting a highly erodible bank and that the flow shear stress alone cannot explain fascines destruction. In no case we observed a structure extraction due to shear stresses, however some conditions led to the complete ruin of structures by scouring in the erodible bank.

Scours could stay a local phenomenon, but could also evolve very quickly to large bank collapse when combined with back erosion. The most relevant external factor contributing to this scouring effect is the possibility of the flow to penetrate and circulate inside the bank. This means that the flow get in and get out the bank, a situation promoted when the erodible bank is scoured and let pass the flow at the base of the structure, or when the bend curvature is high with the main flow perpendicular to the bank.

In a next steep we will focus our investigation in more specific situations promoting the flow circulation, like a succession of hydrograhs, and the bed morphodynamics in presence of sediment transport.

\section{References}

Ashmore, P., W. Bertoldi, and J. T. Gardner (2011), Active width of gravel-bed braided rivers, Earth Surface Processes and Landforms, 36, 1510-1521.

Perez, M. (2016), Experimental studies of riverbank protections with bioengineering techniques, Master Report, Report, 67 pp, Universitat Politecnica de Valencia.

Proust, S., D. Bousmar, N. Rivière, A. Paquier, and Y. Zech (2010), Energy losses in compound open channels, Advances in Water Resources, 33(1), 1 - 16

Cavaillé, P.; Dommanget, F.; Daumergue, N.; Loucougaray, G.; Spiegelberger, T.; Tabacchi, E. \& Evette, A. Biodiversity assessment following a naturality gradient of riverbank protection structures in French prealps rivers Ecological Engineering, Elsevier BV, 2013, 53, 23-30

Cavaillé, P.; Ducasse, L.; Breton, V.; Dommanget, F.; Tabacchi, E. \& Evette, A. Functional and taxonomic plant diversity for riverbank protection works: Bioengineering techniques close to natural banks and beyond hard engineering Journal of Environmental Management, Elsevier BV, 2015, 151, 65-75

Evette, A.; Labonne, S.; Rey, F.; Liebault, F.; Jancke, O. \& Girel, J. History of bioengineering techniques for erosion control in rivers in western europe Environmental Management, 2009, 43, 972-984

Westoby, M.; Brasington, J.; Glasser, N.; Hambrey, M. \& Reynolds, J. 'Structure-from-Motion'photogrammetry: A low-cost, effective tool for geoscience applications Geomorphology, Elsevier, 2012, 179, 300-314 